\title{
Organisational learning and the organisational link: The problem of conflict, political equilibrium and truce
}

\author{
Pierre André Mangolte*
}

\begin{abstract}
This article addresses the issue of organisational learning. The starting point for the analysis is the definition of organisational learning proposed by Levitt and March (1988) in terms of the transformation of an organisation's routines. This definition leads to a focus on the 'organisational link' or the way in which individual routines and various learning processes are coordinated, thus assuring a degree of organisational coherence. In comparing the different organisational theories of Simon (1947), March and Simon (1958), Cyert and March (1963) and Nelson and Winter (1982), it is demonstrated that those authors that place primary emphasis on the organisation as an processor of information tend to downplay the importance of the social, relational and political dimensions of organisation behaviour. Recognition of the dual nature of the organisational link and of the importance of political determinants leads to the conclusion that individual processes of learning and inference should to be analytically distinguished from 'learning' in the sense of a transformation in the organisation's routines.
\end{abstract}

\section{Introduction}

The subject of organisational learning immediately brings to mind a certain number of empirical facts: Adam Smith's pin factory and his reference "to the increase of dexterity in every particular workman" (Smith, 1776, p. 112) which resulted from specialisation and continuous application of the same tasks; the learning curves based on Taylor's theories, drawn by engineers for workshop tasks, at the beginning of the century; or yet again "experience curves", established in the 1930's in the aeronautical industry, curves recording the reduction of direct work costs as a function of cumulated production growth.

In order to explain this type of regularity in a plausible and convincing way, the phenomenon of "learning" linked to direct experience gained in production is invoked. The worker in the pin factory, the employee timed in his tasks by the method officer or the group of workers, technicians and foremen at the aircraft factory accumulating knowhow as they work. In each case, the practices used are improved. The complete set of these learning by doing processes results in an increase in productivity.

\footnotetext{
* CREI - Université Paris-Nord, Avenue Jean-Baptiste Clément, 93430 Villetaneuse, France.

E-Mail: p.a.mangolte@wanadoo.fr

Keywords : Organisational learning, organisation theory, firm, coordination.
} 
However, the examples above fall into two categories. In one case, the individuals are considered in isolation even if they are part of an organisational framework; in the other, the organisation is considered per se (the aircraft factory for example), where the performance of the entire unit is considered. In the latter case, the learning process refers to the entire organisation. By applying the term learning to such very different situations, both the individual and the group effect seem to be considered indifferently.

However, in any organisation (such as the aircraft factory), not only are there obviously a number of individuals who pool their own experience, but also systems, arrangements or co-ordination procedures to enhance contacts between the workers involved and which define the organisation as such and as a specific, united and ordered reality.

Even if the result, namely an increase in productivity, seems the same (measured either individually and on a group basis), is it possible to group together under the same "learning" heading, two processes which would a priori imply differences? This question will be considered in this paper from an organisational learning point of view.

The current theoretical literature on the subject of learning is based on concepts of learning which are generally far more complex and extensive than the simple process of learning via direct experience within one's personal activity. Nevertheless, one sees the same tendency to conflate the processes affecting individuals (humans) and the processes which affect organisations - to a certain extent one sees this in the use made of the concept of learning as soon as the term is applied to an entire organisation.

For example, today the principle of "organisational learning" (Levitt and March, 1988) includes certain behavioural or evolutionary approaches (Nelson and Winter, 1982; Marengo, 1992, 1995). This has raised the theoretical problem of how the systems, procedures, rules and routines which make up the organisation (and which provide fairly consistent links between the different individual members of the organisation), evolve during the learning process. The nature and logic of the evolution of these links are central questions for a theoretical approach to organisational learning.

This paper will try to present the way in which certain theories of organisation have treated the problem of the organisational link, in order to highlight the difficulties which inevitably confront organisational learning theories. Particular attention is given to the evolutionary analysis of the firm in terms of routines (Nelson and Winter, 1982; Nelson, 1994) and to other older analyses of organisations considered as systems for information processing (Simon, 1947; March and Simon, 1958). The aim of the paper is to show that the problem of the necessary consistency and co-ordination of individual learning in organisational learning brings to the fore a theoretical problem which was tackled to a certain extent by Cyert and March (in 1963) as part of their work on the analysis of organisations in terms of information processing. This is the issue of "conflict" or more generally of the existence of a political and social dimension underlying organisational realities. By returning to so-called, "old" concepts it is possible to cast some new light on the current debate on the subject of organisational leaning.

In Section 1, the term organisational learning will be defined for the purposes of the article, with a brief review of the various problems posed by the concept. As the question of an 'organisational or institutional link' is central to the debate, the second section examines how theories of organisation in terms of information processing have tackled the question (March and Simon, 1958; Cyert and March, 1963). Section 3 considers the way 
in which the issue has been treated by Nelson and Winter (1982). Finally the implications of this aspect of the problem for organisational learning will be discussed in Section 4.

\section{Organisational learning raises the problem of the organisational link}

\section{Definition of organisational learning}

Levitt and March (1988) defined organisational learning as an evolution of the routine processes in the organisation over time. "The generic term "routines" includes the forms, rules, procedures, conventions, strategies and technologies around which organisations are constructed and through which they operate. It also includes the structure of beliefs, frameworks, paradigms, codes, cultures and knowledge that buttress, elaborate and contradict the formal routines" (Levitt and March, 1988, p. 320). In this approach, organisational behaviour can always be explained by the different routines.

Levitt and March cite Cyert and March (1963) and Nelson and Winter (1982) as important references here. Neither the validity this nor of the very extensive definition of the term "routine" they propose will be discussed in this paper. The term routine does not cover exactly the same concepts in the work by Nelson and Winter, Cyert and March or even Simon (1945), who also occasionally refers to the "routines of the organisation" (on this point, see Mangolte, 1998).

The argument put forward by Levitt and March (in 1988) is arguably closer in spirit to that of Nelson and Winter (1982) than to that of Cyert and March (1963). The essential thing which is common to them, however, is the idea that the behaviour of the organisation rests on two principles: (a) First, the principle that organisational behaviour is determined by existing routines. This is "a logic of appropriateness or legitimacy more than a logic of consequentially or intention"; (b) Secondly, a principle of heredity or permanence over time. "Routines are based on interpretations of the past more than anticipations of the future" (Levitt and March, 1988, p. 320).

Routines are also put forward as characteristics of the organisation in their own right; as such they are "independent of the individual actors who execute them and are capable of surviving considerable turnover in individual actors" (Levitt and March, 1988, p. 320).

Organisational learning is thus defined as a process whereby organisational routines are transformed over time. This process is driven, since the behaviour of the organisation is linked to targets and is dependent on the deviation between these targets and the results actually achieved (success/failure). "Organisations are seen as learning by encoding inferences from history into routines that guide behaviour" (Levitt and March, 1988 , p. 320). The individuals (humans) are merely carriers of certain organisational routines - together with other components of the organisation (technologies, codes, cultures, etc.). These routines define the organisation and its behaviour.

This emphasis on the routines of the organisation obviously distinguishes this approach to organisational learning from other approaches which only focus on individual learning in an organisational framework (Argyris and Schön, 1978, for example). From the outset, centre place is given in the analysis to all those features of the organisation 
- its structures, coherence and unity - which can be considered to be embodied in routines. In this approach, therefore, the behaviour of the organisation at any given moment (the effective activity of a firm for example) is distinguished from underlying factors which generate (and explain) this behaviour, in other words everything which can be classified under "routine".

\section{Multiple "problematics" of organisational learning}

In the theoretical approach sketched above, organisational learning raises three types of questions which can be separated as in Figure 1.

Organisation, the problem of the organisational link and coordination

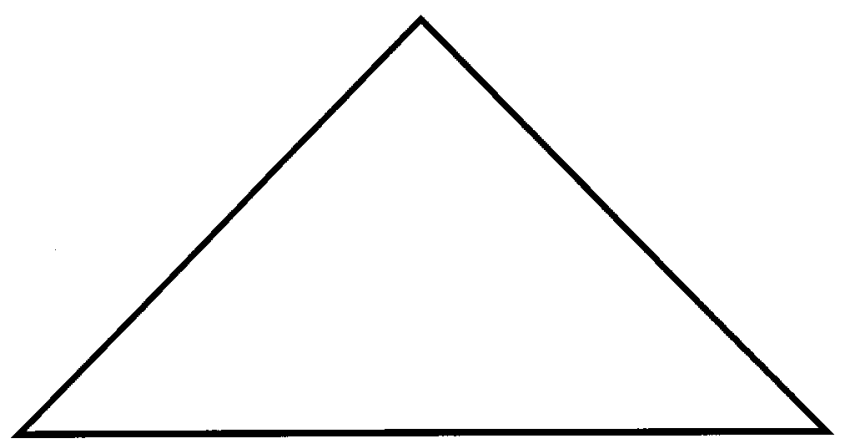

Routines and their cognitive aspect:

which definition, information?

"Learning" as a process in time: knowledge? which process? one or several processes?

competence?

Fig. 1. Three types of problem associated with organisational learning.

This paper will not focus at all on one of the points of the triangle, namely the definition of routines as "memories", or to quote Levitt and March "encoding inferences from history". The theories of Simon, March and Cyert, and Nelson and Winter can then be grouped under the same heading despite the fact that their cognitive approaches are in many respects completely different. In particular, the introduction of the notion of "tacit knowledge" in Nelson and Winter's book completely upturns all previous approaches in terms of information processing; however none of this is essential for the discussion here.

We will focus on the "organisation" point of the triangle and its relationship with learning (the lower right-hand point of the triangle). The problem of the transformation of routines must be considered from the viewpoint of the organisation. The problem here is that of the co-ordination and coherence of all the different individual routines; this also implies a problem with assuring mutual co-ordination and coherence between the various learning processes.

Levitt and March clearly identify two (principal) mechanisms which result in a transformation of the routines - in other words which lead to organisational learning: (1) trial 
and error experimentation, which is a response to the daily pressures of the direct experience of the organisation and (2) organisational search where the organisation draws from a bank of existing alternative routines and adopts the best (Levitt and March, 1988, p. 321). In this rather abstract specification of two organisational learning processes, there is on the one hand, search that may be planned and centralised which can be the work of one person or a specific department within the organisation. On the other hand, the process of incremental accumulation of knowledge is, as a general rule, neither planned, directed, nor regulated from any central point. The problem of the coordination and coherence of the different separate learning actions is clearly stated, provided we are referring to learning within the organisation.

Obviously, the starting point must be the fact that the organisation cannot be considered to automatically benefit from internal unity. On the contrary, the definition we have used is that of March and Simon, which is as good as any other: "Organisations are systems of co-ordinated action among individuals and groups whose preferences, information, interests or knowledge differ. Organisation theories describe the delicate conversion of conflict into co-operation, the mobilisation of resources, and the co-ordination of effort, that facilitate the joint survival of an organisation and its members" (March and Simon, 1993, p. 300).

The central problem is the constitution and maintenance of the unity of the organisation. Even if that unity exists at a certain moment in time, it is inevitably challenged by the learning process. Which factors are responsible for maintaining "cooperation" and "coordination of effort" from one time period to the next? Which specific factors are responsible for maintaining coordination during the learning process, given that the principle of heredity (embodied in routines) is itself affected by learning? What is the nature of the organisational link?

March and Simon give priority to the analysis of the organisational link in informational terms while Nelson and Winter emphasise the cognitive dimension. The social and political dimensions of the organisation are put to one side without being entirely eliminated. The organisational link can therefore be divided into two parts as illustrated in Figure 2. These two parts are the cognitive (or informational) link and the political link. This second dimension is then presumed to be invariable; only the cognitive dimension is subjected to analysis and theory.

It will be useful to return to some of the details of these organisational theories in order to see how different authors have tackled the question by separating the two dimensions described above (see Fig. 2). Only Cyert and March (1963) have tried to articulate these two analytical dimensions. It is necessary to consider the two dimensions together if organisational transformations are to be properly understood.

\section{From Simon to Cyert and March: Organisational equilibrium threatened by conflict}

Simon (1947), March and Simon (1958) and to a lesser extent Cyert and March (1963), base their analysis of organisational phenomenon on the idea that there are limits to human capacity for rational decision making. The organisation is primarily perceived as 


\section{The organisational link}

(Coordination, coherence of routines and effective unity of the organisation)

\begin{tabular}{|c|c|c|c|}
\hline & A cognitive link & $\begin{array}{c}\text { A social and political } \\
\text { link }\end{array}$ \\
\hline (A) static version & $\begin{array}{c}\text { (1) information } \\
\text { processing } \\
\text { or implementation of } \\
\text { knowledge }\end{array}$ & $\begin{array}{c}\text { Activation of } \\
\text { existing routines }\end{array}$ & $\begin{array}{c}\text { (2) invariance in the } \\
\text { social relationships in } \\
\text { an organisation }\end{array}$ \\
\hline (B) dynamic version & $\begin{array}{c}\text { (3) evolution of changes } \\
\text { in the cognitive } \\
\text { dimension (learning in } \\
\text { the strict sense) }\end{array}$ & $\begin{array}{c}\text { Transformation of } \\
\text { routines }\end{array}$ & $\begin{array}{c}\text { (4) conflicts and the } \\
\text { transformation of the } \\
\text { social link in an } \\
\text { organisation } \\
\text { [learning?] }\end{array}$ \\
\hline
\end{tabular}

Fig. 2. An analysis of the organisational link based on two dimensions.

a system which processes information: "in man as much as in organisations, everything is a matter of decision processes and problem solving [...] and in order to make decisions and to solve problems, information must be processed; in short, everything is based on the processing of information" (Simon, 1947, p. 38). Organisational structures (the division of labour, the system of authority, communication channels, etc.), the rules, procedures, standard practices, training and indoctrination of the members are seen as just so many means for taking decisions at all organisational levels:

"The organisations that human beings have constructed in the modern world to carry out the work of production and government can only be understood as machinery for coping with the limits of man's abilities to comprehend and compute in the face of complexity and uncertainty"' (Simon, 1979, p. 501).

The organisation is seen as a tool serving a specific target with the individuals being the tools of the organisation. As Simon (1947, p. 108) puts it, "The behaviour of individuals is the tool with which the organisation achieves its targets". However, this does not mean that the targets of individuals and the targets of the organisation must automatically coincide - nor should the individuals be confused with the posts they occupy. March and Simon - unlike Barnard (1938) - state that if the individual achieves his own target (income for example) by means of the organisation, his personal aims are not confused with the targets of the organisation. Thus, the behaviour of the individual is neither automatically cooperative nor of the type which allows decisions to be taken at the level of the organisation as a whole. In other words the behaviour of the individual is not necessarily compatible with the "survival" of the organisation.

The structures and "routines" of the organisation must be considered at this point. They define the situations and constitute premises for the different decision processes of individuals - more generally speaking the individual units of the organisation. Dividing 
up very general problems into smaller sub-problems according to the specialisation of functions, allows individuals to focus their attention on these sub-problems. Decisions are taken within this (limited) framework and the general and abstract targets of the organisation are replaced by real, measurable targets which can be processed by the various individuals (or basic units of the organisation) involved, within the framework of their individual cognitive limits. The final decision is thus to a large extent pre-determined by the structures.

The structures and procedures which allow for organisational decisions to be taken then become the object of study and analysis in their own right. Comparison is constantly established between the function of the human brain (thinking processes and human heuristics), the computer (with its programs) and the organisation (with its rules). This follows from the view that, "the basic features of the structure [of the organisation] derive from the characteristics of human problem-solving processes and rational human choice" (Simon, 1947, p. 165).

The general principle of an organisation, designed as an information processing system, can be further refined. Organisational decisions are arranged in a kind of continuum. At one extreme there are the totally programmed decisions (the "execution schemes") such as processing an order or following machining instructions (developed by the Methods Department); at the other extreme there are the non-programmed decisions which involve all problems which are not structured at the outset, such as the launch of a new product or modifying execution instructions, etc. Decision-making intervenes when satisfactory solutions are sought within a framework of limited rationality.

\section{The "Barnard-Simon" organisational equilibrium}

As March and Simon (1958) have observed, even the existence of all the structures and procedures taken together cannot explain the existence of cooperation around a common target, which, nonetheless, is essential for any adequate theory of organisational decision making. In order for the functioning of an organisation to be analytically equivalent to a data processing system, the individuals in the organisation must accept the targets of that organisation, or simply the sub-objectives that correspond to their place in the organisation. In this approach, the individuals must identify psychologically with the targets. The social, relational and conflict dimensions of the organisation which are not compatible with on-going organisational "problem solving" must disappear or be neutralised. Only then can a formal analogy be set up between the organisation, the computer and the human brain, which according to Simon constitute three archetypal examples of symbol processing systems.

In 1958, the problem was solved by a specific theory of the organisational link or connection which allows individuals to be assimilated to their prescribed roles in the organisation. By definition this role is coherent with the targets of the organisation. This is the "Barnard-Simon" theory on the equilibrium of the organisation. According to this theory "each participant will continue his participation in an organisation only so long as the inducements offered him are as great or greater (measured in terms of his values and in terms of the alternatives open to him) than the contributions he is asked to make" (March and Simon, 1958, pp. 103-104). The organisation can only survive if the balance between 
the advantages and the contributions is such that the individuals participating in the organisation choose not to leave it and accept to assume their organisational role fully.

This theory could be interpreted as a specific analysis of the social link of the organisation. However, in the opinion of Simon, this amounts to a theory of motivations which assumes a specific psychological attitude among the members of the organisation, namely "loyalty". This attitude is considered independent of all considerations of either direct or indirect interest. The strength of "organisational loyalty" is the factor which ensures the "identification" of the individuals to the targets and to the culture of the organisation. All this is enhanced by the existence of certain permanent psychological characteristics specific to human beings, or at least some human beings. This is what Simon describes as "docility" or "open-mindedness". In certain contexts, "docility" can include the enthusiasm exhibited by an individual to obey and conform; however in more general terms it is the propensity of an individual to enter into a process of adaptive learning, imitating others, accepting social influences and the organisation as it is, and to thus construct his own decisions. Simon doesn't hesitate to suggest that this "docility" is the result of natural selection. The individuals most likely to survive in social life are those who possess the highest levels of what is known as docility. "That fitness [of an individual] is derivable from being docile becomes evident when we consider the opposite to docility: intractability, unmanageability, unteachability, incorrigibility" (Simon, 1991, pp. 35-36).

\section{The firm (and the organisation) as a coalition}

In 1963, Cyert and March tried to go further by discarding "de facto" the hypothesis of the psychological identification of individuals to the organisation and the "BarnardSimon" theory of organisational equilibrium. Nonetheless, the starting point for their work was the same. The firm (or organisation) is defined "as an information-processing and decision rendering system" (Cyert and March, 1963, p. 20). However, they immediately invoke the problem of individual and organisational "goals", thus questioning the hypothesis of the psychological identification of individuals to their organisational roles.

How, they question, can the creation of "organisational goals" be explained, when only "people (i.e. individuals) have goals" and "collectivities of people do not [have goals]"? How can these goals be specified without the existence of an "organisational mind" starting from the goals existing in different "individual human minds" (Cyert and March, 1963, p. 27)? These two questions underline a certain incoherence in the orthodox approach to the firm. On the one hand, there is the claim of methodological individualism, while on the other hand there is a certain practice of reification in the sense of attributing to the firm "goals" and a maximising behaviour that only human individuals should have in this theory. However, the problem constitutes a real theoretical question for Cyert and March. In their opinion, the organisation is a system of conflicts, where the basic units (supposedly coherent in their preferences) have contradictory preference systems with respect to the resources of the system (March, 1962, pp. 18-19).

This leads to a definition of the firm in terms of a "coalition"; a viable coalition of "different" individuals, each having different goals and distinct "orders of preference". This coalition of individuals, occasionally with sub-coalitions, includes "in a business organisation, [...] managers, workers, stockholders, suppliers, customers, lawyers, tax 
collectors, regulatory agencies, and so on" (Cyert and March, 1963, p. 27). In this coalition, there is always a potential internal conflict. This conflict is the result of the divergent goals of the different members of the coalition. In order for the firm to exist and prosper over time, a state of "quasi-resolution of conflict" must be achieved. If the firm is viable, the very conflict movement gives birth to a political process which allows a certain adjustment to be made between several different or contradictory courses of action. The process takes the form of a "bargain", which defines the dominant "coalition" and the "objectives of the organisation", at the same time and in the same movement. The stakes of the bargain are the allocation of resources and the different "payments" (monetary or not) that each member of the coalition wishes to keep or obtain.

"An organisational coalition is viable if the payments made to the various members are adequate to keep them in the organisation. If resources exist to meet all demands and those resources are distributed so as to meet demands, the coalition is a feasible one" (Cyert and March, 1963, p. 36). In general there is a gap between the resources and payments necessary to maintain the coalition, in other words the organisation. This gap is described as the "organisational slack". It provides reserves which allow a "quasi-resolution of the conflict" to be achieved and the establishment of different compromises between the existing interests.

Although the bargaining occurs more or less continuously, the compromises achieved can be more stable than they seem at first sight. In effect, previous compromises are memorised (in the form of rules or precedents) and thus channel the conflict process in the organisation. "The coalition agreements of today are institutionalised into semi-permanent arrangements" (Cyert and March, 1963, p. 34); budget agreements for example. Real changes in the organisation are gradual in general, even if the conflict in the organisation is never totally resolved. The structures, rules and different "routines" of an organisation are thus to a certain extent constructed within the political bargaining process. They are born and evolve in conflicts, give rise to compromises - and are not simply the cognitive human limits developed to deal with incertitude. This approach places emphasis on the institutional constraints which constrain problem solving, particularly while the coalition is being constructed.

\section{Nelson and Winter and the "truce in intra-organisational conflict"}

Nelson and Winter state that 'routine' is a central concept in their theory of firm. Questions about rationality, deliberation and the limits of rational choice tend to disappear because routines are conceived as organisational memories which provide direct information on the behaviour of the members of the organisation. The "logic of appropriateness" takes over from the "logic of consequentiality or intention" 1 . This approach,

\footnotetext{
${ }^{1}$ In Nelson and Winter's (1982) evolutionary theory of economic change, a routine is seen as the equivalent of the biological gene. The "evolutionary process" is defined to be based on three factors: a principle of heredity (gene/routine), a principle of variation (innovation/mutation), and finally a principle of selection.
} 
which is constructed in analogy with the ways in which human beings acquire and implement their know-how and skills, must tackle the problem of organisational coordination much as the previous approach in terms of information processing.

Nelson and Winter provide a solution to this problem different from that of the authors who stress the importance of preferences, motives, psychological predispositions of individuals or even the bargaining process. The organisation's internal conflicts are directly brought into the analysis. Conflict is seen to be a permanent feature of the organisation regardless of whether it is overt or latent. This point leads to the conclusion that the effectiveness of routine performance depends on the existence of an intra-organisational truce (Nelson and Winter, 1982, pp. 107-112).

They start by analysing the operation of an entirely routinised firm which always displays the same behaviour from one period to the next. This is referred to as the model of "circular flow". In a firm which is functioning in this manner, the individuals comprising the company at any given time only need draw on a subset of the memorised routines. "[...] what is required for the organisation to continue in routine operation is simply that all members continue to "know their jobs" as those jobs are defined by the routine. This means, first of all, that they retain in their repertoires all routines actually invoked in the given state of routine operation of the organisation" (Nelson and Winter, 1982, p. 100).

Thus, in order for organisational coordination to exist (and to be maintained) each member of the organisation must know, at any given time, which routine in his repertoire to apply. He must be capable of correctly receiving and interpreting messages either from other members of the organisation or from the surrounding environment. These messages can take many forms: explicit orders (either written or oral), hand signals, gestures, winks, bells or even the simple arrival of the product to be transformed (on a production line for example). In turn the receiver of the message(s) gives similar messages, either directly, in which case it is part of his skill, or indirectly by simply fulfilling his task.

The capacity to interpret and react in an appropriate way to the "messages" which circulate through the organisation constitutes an integral part of individual competence. This capacity is seen to be stored within the individual memories that make up the routines, or to be stored in external memories (files, machines, etc.), which are part of the organisation.

"What is central to a productive organisational performance is coordination; what is central to coordination is that individual members, knowing their jobs, correctly interpret and respond to the messages they receive. The interpretations that members give to messages are the mechanism that picks out, from a vast array of possibilities consistent with the roster of member repertoires, a collection of individual member performances that actually constitute a productive performance for the organisation as a whole" (Nelson and Winter, 1982, p. 104).

In this approach, the organisational link rests first and foremost on a cognitive link. The different pieces of knowledge (articulated or tacit) which are memorised in individual member's repertoires must, at least to some extent, be coherent with one another. Here, coherence means that when activated they result in a unified collective performance, which is itself the expression of a certain degree of organisational coordination. However, this is not sufficient in itself. The existence and maintenance of this coordination - and the different organisational routines - brings us back to the conflicts, the 
"motivations", and more fundamentally to the autonomy of the human beings in the organisation who keep the different routine repertoires. It is thus necessary that the members of an organisation exhibit "willingness" (Nelson and Winter, 1982, p. 104) in the implementation of their routines and that the intra-organisational conflicts be maintained within limits compatible with overall coordination and performance. A "truce" is required here. Nelson and Winter state that organisational routines must be constructed on the basis of a truce if the "circuit" is to operate properly.

Routine operation involves a comprehensive truce in intra-organisational conflict. There is a truce between the supervisor and those supervised at every level in the organisational hierarchy: the usual amount of work gets done, reprimands and compliments are delivered with the usual frequency, and no demands are presented for major modifications in the terms of the relationship. There is similarly a truce in the struggle for advancement, power, and prerequisites among high level executives (Nelson and Winter, 1982, p. 110).

The important thing here is the existence of a certain "adjustment" between the motivations of the members of the organisation and the requirements of the routine operation of the organisation. In addition, this adjustment must be maintained over time, in order that, "the members of the organisation are rarely surprised at each other's behaviour and also that involuntary separations of members from the organisation do not occur" (Nelson and Winter, 1982, p. 108).

We see here the same sorts of problems which confront a theory of the organisation conceived as an information processing system. The solution in terms of the hypothesis of an organisational truce has much in common the "Barnard-Simon" concept of an organisational equilibrium. However, the interpretation given by Nelson and Winter is very different. They directly invoke institutional mechanisms which tend to stabilise the political, social and relational dimension of the organisation. These mechanisms, which are part of the organisational routine, channel behaviour - in other words the way the members of the organisation do or do not implement their own routines.

Among these mechanisms, there are those which enforce the rules of the organisation (rule enforcement mechanisms). Examples of this type of mechanism, which enable routine activity include: the manager's regular or occasional checking up on his employees, routine systems for financial checks and procedures for sanctions (even firing). Such mechanisms provide a barrier to any action which would be too much opposed to the requirements of the organisation and which would consequently represent a threat to any coordinated performance. "In this sense, such rule-enforcement mechanisms are crucial in keeping the underlying conflicts among organisation members from being expressed in highly disruptive forms" (Nelson and Winter, 1982, p. 109).

However, even a highly developed checking and rule-enforcement system cannot completely channel behaviour. There is always ample latitude for the discretionary behaviour of different members of the organisation, and different individual behaviours can be generally associated with differing results for the organisation in terms of performance. And "within the substantial zone of discretion that exists in most cases, the conformity of individual members to organisational requirements is motivated by considerations other than the routinised organisational mechanisms that enforce the rules" (Nelson and Winter, 1982, pp. 109-110). 


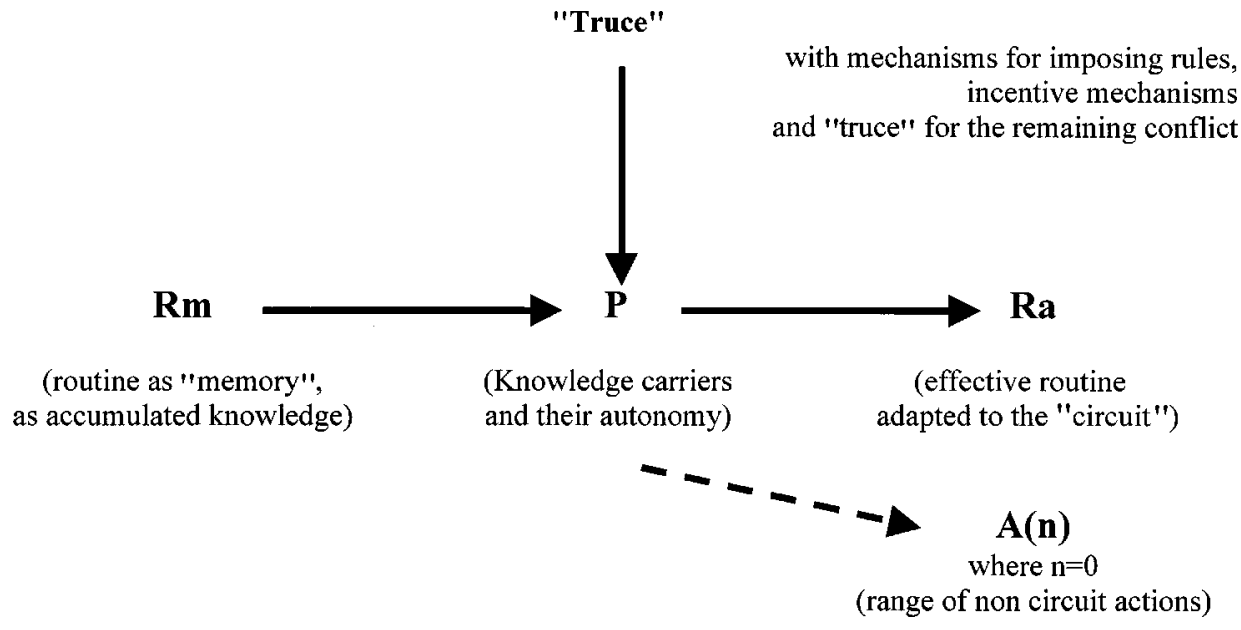

Fig. 3. The "truce" in the activation of routines.

A range of techniques exists to motivate individuals in the deployment of routines, encouraging them to adapt to the requirements and rules of the organisation. These motivating mechanisms (motivators) are added to the coercive mechanisms associated with checks. They contribute to stabilising standard behaviour and maintaining organisational coordination. However, in the opinion of Nelson and Winter, even these mechanisms do not completely neutralise the discretionary element in individual behaviour. Consequently conflict persists. In our diagram (Fig. 3), the complete range of actions $A(n)$ is not automatically empty, $\mathrm{n}$ is not necessarily equal to zero; and certain actions of the members of an organisation invariably can disrupt the "circuit", or even undermine organisational coordination, if only as an unintended consequence. Nelson and Winter thus put forward an intra-organisational truce hypothesis and state that the routines of an organisation are necessarily based on a certain "internal political equilibrium" (Nelson and Winter, 1982, p. 111).

For this reason, in their 1982 volume, the various routines of an organisation could not be analysed simply as "stores of knowledge". The memorisation of the knowledge necessary for effective organisational coordination is not enough to maintain "the circuit" and, more generally, the organisational link. Routines thus necessarily include a truce, and social or institutional rules which determine or channel the use of knowledge and individual behaviour. Organisational routines thus imply both a cognitive and a "motivational/ relational" link (Winter, 1995, pp. 9-10), each with its own evolutionary path.

If the analysis is based on the routines which constitute and maintain organisational coordination, different types of routine can be identified. Some of the routines rely heavily on knowledge. They are of a more technical nature and depend little on a social dimension, neither in their implementation nor in their existence. On the other hand, others are basically defined by their institutional content. They represent a certain stabilisation (which may even be codified) of the various social relations specific to that organisation. 
"When one considers routine operation as the basis of organisational memory, one is led to expect to find routines patterned in ways that reflect characteristics of the information storage problem that they solve. When one considers routine operation as involving a truce in intra-organisational conflict, one is led to expect routines to be patterned in ways that select features of the underlying problem of diverging individual member interests. The obvious example of such patterning is the existence of rule-enforcement mechanisms as an ongoing feature of organisational routine, even when serious breaches of the rules are infrequent and most of the sanctions that are nominally available are not applied" (Nelson and Winter, 1982, pp. 110-111).

\section{Learning or transforming the "routines"?}

We can now turn more directly to the subject of organisational learning. From an analytical point of view, it has been shown that organisational routines comprise two dimensions, namely the cognitive and institutional ones. The (unitary) existence of an organisation generally supposes a certain state of "truce". In other words, it supposes a certain degree of cooperation. This draws into question the validity of the definition given by Levitt and March (1988), and more fundamentally points to the limitations of an analysis of organisational change in terms of learning, which is a process which necessarily operates at an informational or cognitive level and at this level only.

Can all of the following situations be qualified as organisational learning? Can they be assimilated, compared or interpreted in the same way and without taking any special precautions?

(a) Learning to pedal a bicycle (a child of about two and a half for example). This involves the construction of two learning units, the first one for the right foot, the other for the left foot without considering the rest. Any other type of similar learning situation of the same type could be included.

(b) Learning to work as a team (a crew of sailors for example), in a perfectly coordinated way, the oars of a canoe which are responsible for forwards, backwards or stopping movements for example, or any other similar learning experience.

(c) The planned conversion of a mechanical workshop, with redefinition of the different tasks and imposing standards within a Scientific Management framework, the various workers adapting to the new work organisation, and any other similar transformation of routines.

(d) The introduction of more efficient machines and the scrapping of old ones whilst retaining the same workforce, or any other change of the same type

(e) The improvement of practices for different relatively autonomous teams (or why not even for different companies); these teams all working to build a skyscraper, executing the same working plan floor by floor. In this case there are different specific learning tasks and a continuous transformation of the coordination mechanisms (organisational or bargaining) between the teams, the entire process resulting in the work progressing at a regular rate as the building increases in height. And any other similar situation.

(f) The unilateral (or negotiated) modification of the working times and wages within a company and any other similar transformation associated with salaries. 
At first sight, it would seem that the first case can be eliminated as not being an example of organisational learning. In this case there is no organisation (formal or informal). However, from the point of view of a purely cognitive analysis of the organisation, one might argue that such pure problems of coordinating different informational (or cognitive) processes can be appropriately defined as 'organisational learning'. In the case of the child learning to ride a bicycle, the learning tasks are constructed separately (left foot, right foot), and together in a coordinated fashion. From an analytical point of view, the problem of organisational coordination seems to be the same. This allows us to understand more clearly the tendency in the literature to use 'organism' as an analogy for 'organisation' 2 .

In both the example of the child (a) and the sailors (b) there is learning - indeed it is the most important factor in these situations. Here we have the creation of a package of tacit knowledge which must be inscribed in the body-and-mind of the participants in order to generate individual (a) or collective (b) know-how. The only factor which differentiates the two cases is the existence - a necessary condition for learning - of a certain social cooperation in the team of sailors; whereas the "cooperation" between the left foot and the right foot (not to mention the rest), is in principle automatically ensured by the child's own physiological and psychological mechanisms (his "motivation") or, in other words, by the unity of his body-and-mind. On the other hand, the unity of the team of sailors is not a given despite the fact that this unity is a condition of learning; however in this case, to achieve the unity there must be a social agreement, a common willingness (whether spontaneous or imposed by discipline) which allows all the sailors to row together.

Case (e), the skyscraper, is also a situation where learning dominates the situation. This learning is for the coordination of the interventions of the different specialised teams (and even of different companies) in space and time. In fact, this is a classic example which illustrates learning by doing (individual or collective). However, here also, an underlying relational dimension favours (or possibly thwarts) learning. If operations are to flow smoothly, one or several "coalitions" must be formed, to use Cyert and March's expression, which must be interconnected.

Cases (c), (d) and (f) all represent formal organisations (firms) and are examples of the transformation of organisational routines. Hence, the definition put forward by Levitt and March (1988) of organisational learning as a transformation of the organisation's routines can be questioned. If the term "learning" is taken seriously, there should be a transformation in the cognitive dimension of routines and a cumulative and driven process which affects this cognitive dimension. However, it seems absolutely obvious that in the last case (the modification of salary rules), the cognitive dimension is not the most important factor and is in fact negligible. There is no accumulation of experience in this case, and the modification of procedures (which are so many specific routines) has nothing to do with any type of "learning" process. However, the modification does

\footnotetext{
${ }^{2}$ See, for example, Levitt and March (1988), who refer to the "intelligence of organisations" (p. 333); or Cohen and Bacdayan (1994) who, in discussing tacit knowledge, evoke a certain "organisational unconciousness" (p. 556).
} 
challenge the "truce" - which appears to be broken. Analytically speaking, the main question here is the constitution of a new political equilibrium in the organisation.

For cases (c) and (d), the transformation of routines implies a transformation of the cognitive dimension. Consequently, one can talk about "learning" in the strict (and usual) sense of the word. These two examples also illustrate the processes evoked by Levitt and March (1988, p. 321) for the selection of a set of efficient routines from a batch of existing routines. However, the Taylorian redefinition of tasks with imposed standards is of more consequence to the social and political dimension than the other example (d), where in principle, neither the job nor the role definition of the different operators are at stake.

Figure 4 summarises these observations.

It would at first sight seem that the term organisational learning cannot be applied to just any transformation of routines in an organisation. It is not possible to treat every case

\begin{tabular}{|c|c|c|c|}
\hline & $\begin{array}{l}\text { Existence of } \\
\text { one (formal) } \\
\text { organisation? }\end{array}$ & $\begin{array}{l}\text { Importance of the } \\
\text { cognitive processes } \\
\text { (learning in the strict } \\
\text { sense) }\end{array}$ & $\begin{array}{c}\text { Importance of the social and } \\
\text { political dimension } \\
\text { [the logic of conflict] }\end{array}$ \\
\hline (a) the child & NO & dominant & nil (or negligible) \\
\hline (b) the rowers & $\begin{array}{l}\text { NO, } \\
\text { informal social } \\
\text { cooperation }\end{array}$ & dominant & cooperative will \\
\hline $\begin{array}{l}\text { (c) Taylorian } \\
\text { rationalization }\end{array}$ & $\begin{array}{c}\text { YES, } \\
\text { hierarchical } \\
\text { relationship (employee) }\end{array}$ & $\begin{array}{l}\text { implementation of } \\
\text { standards, individual } \\
\text { adaptation }\end{array}$ & $\begin{array}{l}\text { constraint: standards imposed } \\
\text { and/or negotiated; conflict? }\end{array}$ \\
\hline (d) new machines & $\begin{array}{c}\text { YES, } \\
\text { hierarchical } \\
\text { relationship (employee) }\end{array}$ & $\begin{array}{l}\text { knowledge incorporated } \\
\text { into machines, adaptation } \\
\text { for everything else }\end{array}$ & $\begin{array}{c}\text { activation of functional } \\
\text { specialization and the } \\
\text { hierarchical relationship } \\
\text { (authority); very low conflict } \\
\text { situation }\end{array}$ \\
\hline (e) the sky-scraper & $\begin{array}{c}\text { YES, } \\
\text { formal } \\
\text { organisations and trade } \\
\text { relationships }\end{array}$ & $\begin{array}{l}\text { in situ learning: } \\
\text { scheduling, procedures } \\
\text { and coordination, etc }\end{array}$ & $\begin{array}{c}\text { importance of the relationship } \\
\text { dimension in teams and } \\
\text { between companies }\end{array}$ \\
\hline $\begin{array}{l}\text { (f) employment } \\
\text { rules (salaries) }\end{array}$ & YES & negligible & dominant ; conflict \\
\hline
\end{tabular}

Fig. 4. The transformation of routines, some examples and two different approaches. 
as if it was a process of inference or subdivided accumulation of experience. This type of process only affects the so-called cognitive dimension of the organisation.

Of course, the different routines of an organisation are based on acquired and used skills or, in other words, on a stock of stored knowledge. The stock is transformed, and in certain cases this transformation can be characterised as relevant to the learning process in the strictest sense. However, the fact that these same routines are "organisational" most of the time, implies the existence of coordination between the different 'carriers' of routines (human beings), and these carriers always retain a certain level of autonomy in the activation of their repertoires. Consequently, the routines also rely on stabilised social relationships. Here, "truces" (or coalitions) are necessary conditions for the effective and unitary existence of the organisation. One should not confuse these truces analytically with memorised knowledge within the organisation and their processes of evolution must also be distinguished. The logic of "conflict" is not one of learning. Modification in the level of effort or evolution in social relationships within the organisation is neither a simplified version of a process of inference nor a subdivided accumulation of knowledge. It should not be assimilated to such a process.

The subject of organisational learning would thus seem rather ambiguous, even inappropriate or simplified, in that it leads us to consider organisational transformations merely from a cognitive angle, whilst completely ignoring the underlying political and social dimension. Yet this dimension must be included here. In effect, any transformation of routines implies the redefinition of "truces", of "coalitions" and of the social link which is to a greater or lesser extent the foundation of the organisation.

\section{Conclusion}

In all the theories of the organisation (or the firm) which we have discussed above Cyert and March being slightly different to the rest - the accent has been on the informational and/or cognitive dimension which defines the organisation. The organisational unit nonetheless raises the problem of coordination. In the various theories discussed, this leads to another dimension. Simon defines this dimension as psychological and in the other theories discussed it is treated as being social and political; this dimension cannot be merely simplified to information processing or the simple activation of previously stored knowledge.

The existence of an organisational decision process in the approaches which treat the organisation as an information processing systems rests on the hypothesis of an organisational equilibrium (March and Simon). Or it leads to the presentation of the firm as a coalition (Cyert and March). This coalition is formed and maintained in what must be a "quasi resolved" conflict in order for the organisation to exist. Nelson and Winter consider the analytical situation to be somewhat different; the problematic aspect of organisational decision making is replaced by the creation of a routine for the entity. This routine is a product of the ordered activation of different repertoires of knowledge, located here and there in the organisation. However, the same problem appears. The "circuit" cannot exist without an analogous hypothesis. A certain number of institutional conditions and even a "truce for the conflicts" are necessary between the members of the 
organisation. The "relational/motivational" dimension of the firm - which Cyert and March have presented as a political dimension capable of evolution - must be stabilised or neutralised in order to allow the different organisational routines to be deployed in an ordered way.

The theoretical difficulty of analysing the organisation in its informational and cognitive dimension, and only in this dimension, inevitably reappears when the organisation is analysed not only in static terms but also dynamically in terms of changes in different organisational routines. The fact that each routine contains something of the truce leads us to reject a definition of change in organisational routines which would systematically conflate this change with learning (or inference processes). The logic of evolution is different (Coriat and Dosi, 1994). Even when organisational learning is under consideration, when this term is given a specific definition, the situation cannot be analysed without consideration of the social, institutional and political dimensions of the organisations. Unfortunately, this dimension is often ignored and rejected by the organisational learning literature.

\section{References}

Argyris C., Schön D. (1978) Organizational learning, Addison-Wesley.

Barnard Ch. (1938) The functions of the executive, Harvard University Press Cambridge, 1968.

Cohen M.D., Bacdayan P. (1994) Organizational Routines are Stored as Procedural Memory: Evidence from a Laboratory Study, Organization Science 5, p. 554-568.

Cyert R., March J. G. (1963) A Behavioral Theory of the Firm, Prentice-Hall Inc.

Coriat B., Dosi G. (1994) Learning how to govern and learning how to solve problems: On the co-evolution of competences, conflicts and organizational routines, unpublished working paper, Prince Bertil Symposium, Stockholm School of Economics.

Levitt B., March J.G. (1988) Organizational learning, Annual Review of Sociology 14, pp. 319-340.

Mangolte P.-A. (1998) Le concept de "routine organisationnelle" entre cognition et institution, Thèse pour le doctorat en sciences économiques, Université Paris XIII.

March J.G., Simon H.A. (1958) Organizations, 2nd edn, B. Blackwell, Cambridge, 1993.

March J.G. (1962) The business firm as a political coalition. In: Décisions and organizations, B. Blackwell, Oxford, 1990.

March J.G., Simon H. (1993) Organizations revisited, Industrial and Corporate Change 2, pp. 299-316.

Marengo L. (1992) Coordination and organizational learning in the firm, Journal of Evolutionary Economics 2, pp. 313-326.

Marengo L. (1995) Structure, Competence and Learning in an Adaptive Model of the Firm. In: Dosi, Malerba (Eds), Organization and Strategies in the Evolution of the Entreprise, pp. 124-154.

Nelson R.R., Winter S.G. (1982) An Evolutionary Theory of Economic Change, Harvard University Press.

Nelson R.R. (1994) Firm, Theory of the (II), in: The Elgar Companion to Institutional and Evolutionary Economics, pp. 241-246.

Simon H.A. (1947) Administrative Behavior, 3rd edn, Free Press, New York, 1976. 
Simon H.A. (1979) Rational Decision Making in Business Organizations, American Economic Review, 69, pp. 493-513.

Simon H.A. (1991) Organizations and Markets, Journal of Economic Perspectives 5, pp. 25-44. Smith (1776) The Wealth of Nations, books I-III, Penguin Books, 1970.

Winter S.G. (with Cohen, Burkhart, Dosi, Egidi, Marengo, Warglien) (1995) Routines and other recurring action patterns of organizations: Contemporary research issues, unpublished working paper, November, Santa Fe.

to access this journal online: www.edpsciences.org 